\title{
Diagnóstico diferencial de nódulos pulmonares cavitados: a propósito de un caso clínico
}

\author{
DANIEL ERLIJ O.*, SUSANA MICHALLAND H.*, OSCAR NEIRA Q.*, \\ VERÓNICA WOLFF C.*, VIVIANA JARA B.** y MANUEL MENESES C.***
}

\section{Differential diagnosis of cavitary pulmonary nodules: a propos of a clinical case}

The differential diagnosis of cavitary pulmonary nodules is a great challenge, where the clinical context in addition to the image studies and laboratory tests are part of the key tools to guide the diagnostic process through 4 major etiological groups: infectious, neoplastic, rheumatologic and miscellaneous. We describe a case of a heavy smoker and complicated diabetic patient with cavitary pulmonary nodules, with a clinical context that induces certain etiologies such as infectious and neoplastic, but whose biopsy was compatible with Granulomatosis with polyangiitis (ex Wegener's granulomatosis), without a clinical exam nor laboratory tests suggesting this finding.

Key words: Cavitary pulmonary nodules, Granulomatosis with polyangiitis (Wegener's granulomatosis).

\section{Resumen}

El diagnóstico diferencial de nódulos pulmonares cavitados constituye un gran desafío en el cual, la clínica, la imagenología y los exámenes de laboratorio permiten una orientación etiológica en cuatro grandes grupos: infecciosa, neoplásica, reumatológica y miscelánea. Presentamos el caso de una paciente gran fumadora y portadora de una diabetes mellitus descompensada, con nódulos pulmonares cavitados, en la cual el contexto clínico obligaba a plantear ciertas etiologías como las infecciosas y neoplásicas, pero cuya biopsia fue compatible con Granulomatosis con Poliangeítis (ex Granulomatosis de Wegener), sin una clínica ni exámenes de laboratorio concordantes con dicho hallazgo.

Palabras clave: Nódulos pulmonares cavitados, Granulomatosis con poliangeítis (Granulomatosis de Wegener).

\section{Caso clínico}

Paciente mujer de 53 años, dueña de casa, portadora de diabetes mellitus tipo 2 en tratamiento irregular con metformina y mal control metabólico, hipertensión arterial en tratamiento con enalapril y fumadora activa con índice de 60 paquetes/año.

Presenta un cuadro de seis meses de tos con expectoración mucosa, sin hemoptisis ni síntomas sistémicos. Consulta por un episodio de dolor torácico tipo puntada, con tope inspiratorio, de inicio súbito. A su ingreso, se encuentra hemodinámicamente estable, afebril, con una saturación basal de oxígeno de $95 \%$ y un examen físico donde sólo destacaban lesiones vesiculares sobre el glúteo izquierdo, compatibles con infección por Virus Herpes Zóster. En la radiografía de tórax (Figura 1), se observó múltiples imágenes nodulares, algunas de ellas cavitadas, en ambos campos pulmonares.

Entre los exámenes generales, destacó un hemograma normal, VHS de $61 \mathrm{~mm} / \mathrm{h}$, PCR de 46 $\mathrm{mg} / \mathrm{L}$ (normal: entre $0-5 \mathrm{mg} / \mathrm{L}$ ), glicemia de 638 $\mathrm{mg} / \mathrm{dL}$, creatininemia de $1,3 \mathrm{mg} / \mathrm{dL}$, natremia de $129 \mathrm{mEq} / \mathrm{L}$, kalemia de $5,5 \mathrm{mEq} / \mathrm{L}$, examen de orina con 1-3 eritrocitos por campo, 5-7 leucocitos por campo, proteinuria $(+++)$, glucosuria $(+)$.

En relación a los hallazgos radiológicos, se realizó una tomografía axial computada de tórax, (Figura 2) que evidenció múltiples nódulos, la mayoría cavitados, comprometiendo gran parte del parénquima de ambos pulmones, sin adenopatías mediastínicas ni otros hallazgos.

\footnotetext{
* Sección de Reumatología, Hospital del Salvador y Facultad de Medicina, Universidad de Chile.

** Servicio de Medicina, Instituto Nacional del Tórax.

*** Departamento de Anatomía Patológica, Instituto Nacional del Tórax.
} 


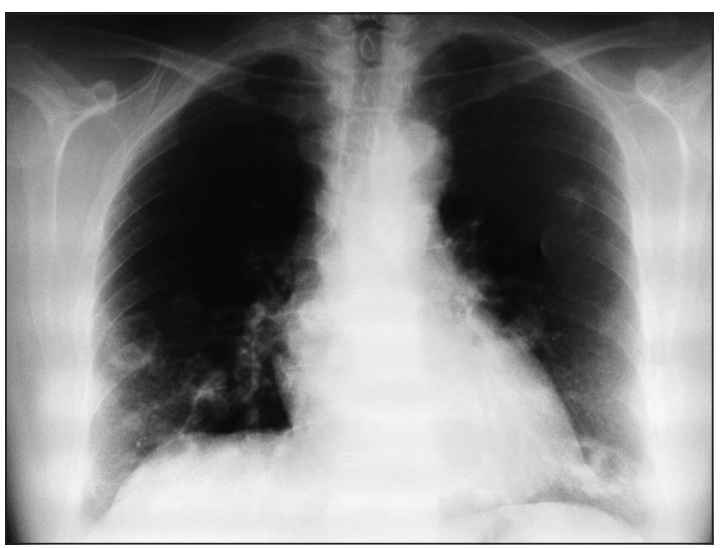

Figura 1. Radiografía de tórax que muestra múltiples imágenes de nódulos pulmonares cavitados en ambos campos pulmonares.

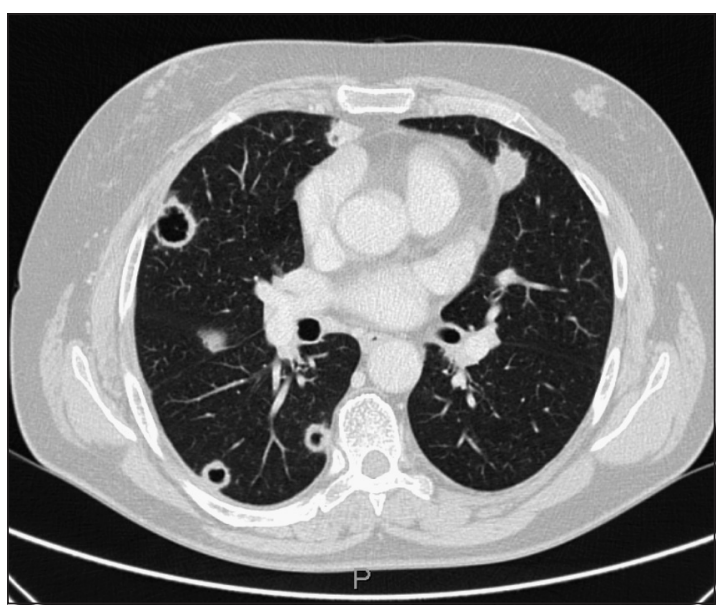

Figura 2. Tomografía axial computada en la cual se observan 16 imágenes nodulares cavitadas distribuidas tanto central como periféricamente en ambos campos pulmonares. La mayor de ellas mide 2,2 cm en su eje mayor, con paredes de grosor de hasta $0,5 \mathrm{~cm}$. No se observaron adenopatías mediastínicas asociadas.

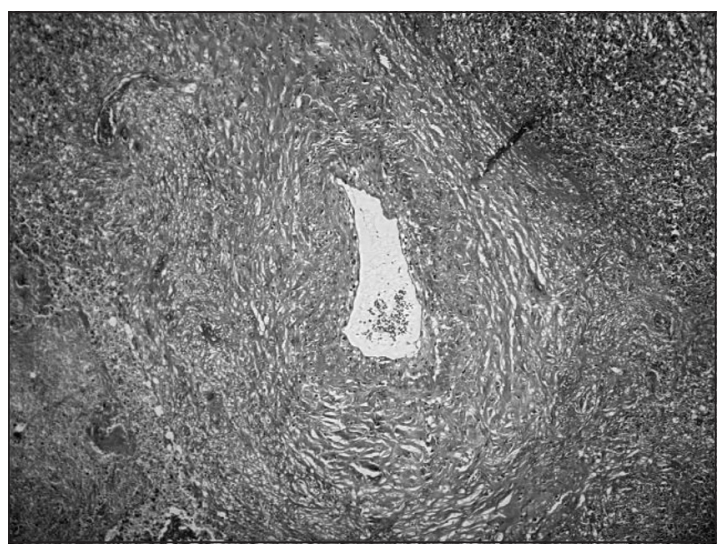

Figura 3. Biopsia de tejido pulmonar. Se observa vaso con proceso destructivo reparativo de la pared (Hematoxilina-eosina) $40 \mathrm{X}$.
Como parte del diagnóstico diferencial de nódulos pulmonares cavitados, se solicitó evaluación por reumatología, infectología y ecocardiograma.

$\mathrm{Al}$ interrogatorio de síntomas reumatológicos, sólo refiere artralgias generalizadas de larga data, sin manifestaciones sistémicas, oculares, rinosinusales, urinarias ni neuropáticas. A pesar de ello, se determinó anticuerpos anti citoplasma de neutrófilos (ANCA) por inmunofluorescencia indirecta, resultando positivo débil, con un patrón perinuclear (ANCAp). El ANCA por ELISA, para PR3 y MPO fue negativo. Los anticuerpos antinucleares (ANA) fueron negativos y el complemento (C3 y $\mathrm{C} 4)$ fue normal.

En el estudio de búsqueda de un factor infeccioso, la serología para virus de hepatitis B, C y VIH fue negativa. La serología para Aspergillus fue negativa. Se realizó una fibrobroncoscopía, la cual fue normal. El lavado bronquioalveolar permitió realizar cultivos para bacterias y hongos, los cuales fueron negativos, al igual que las baciloscopías. El recuento celular fue de $65 \times 10^{6}$ con $74 \%$ de macrófagos. No se tomaron biopsias transbronquiales, porque las lesiones no estaban al alcance de esta técnica.

El ecocardiograma transtorácico no evidenció fuente embolígena. Se decide finalmente realizar una biopsia de los nódulos pulmonares por videotoracoscopía, la cual debió convertirse a una cirugía abierta por sangrado.

En la biopsia se describe un parénquima pulmonar con extensas zonas de necrosis rodeadas por un denso infiltrado inflamatorio crónico, con una barrera de células epitelioides de hábito histiocítico y presencia de vasculitis de pequeño y mediano vaso, compatible con un cuadro de Granulomatosis con poliangeítis (ex Granulomatosis de Wegener) (Figura 3).

En la evolución destacó el ascenso de la creatininemia a $2,5 \mathrm{mg} / \mathrm{dL}$, y la aparición de hematuria de 13-15 eritrocitos por campo, cilindros granulosos, céreos y leucocitarios escasos.

En este contexto se decide iniciar tratamiento con prednisona $0,5 \mathrm{mg} / \mathrm{kg} /$ día vía oral, asociado a ciclofosfamida $50 \mathrm{mg} /$ día vía oral y al uso de insulina NPH para lograr un control metabólico adecuado. La paciente presentó una evolución favorable, estabilizando su función renal, con creatininemia al año de $1,6 \mathrm{mg} / \mathrm{dL}$ y ausencia de signos de actividad de su vasculitis. Actualmente en tratamiento con azatioprina $100 \mathrm{mg} /$ día y prednisona $5 \mathrm{mg} /$ día.

\section{Discusión}

El diagnóstico diferencial de los nódulos pulmonares cavitados es un desafío diagnóstico que 
obliga a plantear una gran variedad de etiologías de acuerdo a la anamnesis, examen físico y evolución de las lesiones.

La principal herramienta para su evaluación es la tomografía axial computada (TAC), idealmente helicoidal, la cual detecta hasta $40 \%$ más lesiones que la TAC convencional ${ }^{1}$. Si bien, el seguimiento de las lesiones en el tiempo mediante TAC es de utilidad para determinar su comportamiento y orientar sobre la etiología, este recurso imagenológico no permite, por sí solo, un diagnóstico definitivo, y se requiere de elementos clínicos y de laboratorio adicionales.

El espectro etiológico de los nódulos pulmonares cavitados es amplio, y es posible ordenarlo en cuatro grandes causas: infecciosas, neoplásicas, reumatológicas y misceláneas.

Entre las causas infecciosas, destacan aquellas provocadas por bacterias. Si bien está ampliamente descrito que microorganismos como la Klebsiella pneumoniae, pueden provocar neumonía necrotizante, ésta es más frecuente en las neumonías por Streptococcus pneumoniae y Haemophilus influenzae $^{2}$. El Staphylococcus aureus meticilino resistente (SAMR) de la comunidad es una causa emergente. Los abscesos bacterianos por anaerobios, la Nocardiosis, la Actinomicosis y la embolía pulmonar séptica o no séptica pueden causar nódulos pulmonares cavitados en pacientes susceptibles $^{1,2}$. Los pacientes inmunosuprimidos tienen mayor susceptibilidad a la cavitación de las lesiones infecciosas, lo cual incluye a pacientes con Diabetes Mellitus descompensada ${ }^{2}$. Pueden también manifestarse de esta forma, algunas infecciones fúngicas como la Mucormicosis, Aspergilosis, Coccidioidomicosis, Criptococosis, Histoplasmosis o incluso aquella por Pneumocystis jirovecci, así como también, infecciones parasitarias como la Hidatidosis y la Paragonimiasis. Las lesiones nodulares infecciosas pueden ser granulomatosas o no granulomatosas. Las granulomatosas constituyen el $80 \%$ de los nódulos solitarios benignos y se relacionan generalmente a Mycobacteriosis, Histoplasmosis y Coccidioidomicosis. La primera de ellas, de especial importancia en nuestro país, en particular cuando el compromiso es de lóbulos superiores, con imágenes nodulares que pueden superar los $5 \mathrm{~mm}$.

En relación a las causas neoplásicas, un nódulo solitario cavitado tiene mayor probabilidad de ser una lesión maligna. Se ha considerado que paredes con grosor menor a $4 \mathrm{~mm}$ son sugerentes de benignidad, mientras que valores mayores a $10 \mathrm{~mm}$, suelen asociarse a lesiones malignas. Sin embargo, esta aproximación es incierta ${ }^{2}$. Por otro lado, se ha descrito que las lesiones interlobares y las relacionadas a pleura visceral tienden a ser benignas. El cáncer primario de pulmón tiende a mostrar cavitación en el $22 \%$ de las imágenes de TAC y en el $11 \%$ de las radiografías ${ }^{2}$. Las metástasis se tienden a cavitar menos que las neoplasias primarias (menos de un $4 \%$ ) y en general aparecen en las bases pulmonares y subpleurales, como lesiones de bordes irregulares. La cavitación es más frecuente en el cáncer pulmonar de células escamosas ${ }^{1,2}$. No es raro encontrar lesiones primarias sobreinfectadas, por ejemplo, con tuberculosis, lo cual dificulta aún más el diagnóstico diferencial ${ }^{2}$. El aporte de la imagenología debe ser evaluado con criterio para evitar errores diagnósticos. A modo de ejemplo, si llega a asumirse que una lesión de crecimiento lento es indudablemente benigna, lesiones malignas como el carcinoide y cáncer bronquioalveolar, que pueden ser de lento desarrollo, recibirían un enfrentamiento terapéutico tardío. De ahí que el aporte de la radiología en la orientación diagnóstica no reemplaza al estudio complementario que habitualmente requerirá de la biopsia, herramienta que permitirá alcanzar el diagnóstico definitivo ${ }^{2}$.

Son numerosas las enfermedades reumatológicas que presentan manifestaciones pulmonares al inicio o en el curso de la patología, sin embargo, la presencia de nódulos cavitados es inusual. La excepción está dada por la Granulomatosis con poliangeítis (GPA), antiguamente llamada Granulomatosis de Wegener. En esta entidad, hasta el $49 \%$ de los nódulos pulmonares pueden cavitarse. Habitualmente son de pared gruesa e irregular, presentan un centro necrótico y pueden presentar sobreinfección bacteriana hasta en un $16 \%$. La biopsia es diagnóstica cuando muestra granulomas necrotizantes con signos de vasculitis necrotizante y capilaritis ${ }^{2-5}$. Presenta ANCA positivo hasta en $90 \%$ de las formas sistémicas y $60 \%$ en la localizada ${ }^{6}$. El $90 \%$ son de patrón citoplasmático (ANCAc) mediante inmunofluorescencia y contra antígeno PR3 al ser determinados mediante ELISA ${ }^{3,6}$. La sarcoidosis se manifiesta con nódulos cavitados en menos del $7 \%$ de los $\operatorname{casos}^{2}$ y habitualmente su morfología simula enfermedad metastásica. El síndrome de Churg-Strauss habitualmente se manifiesta con compromiso pulmonar micronodular y rara vez se cavita ${ }^{2,7}$. Se han descrito lesiones cavitadas en otras enfermedades como la amiloidosis primaria, la espondilitis anquilosante, la artritis reumatoídea, la poliarteritis nodosa y el lupus eritematoso sistémico, siempre bajo la consideración de la posibilidad de etiología infecciosa en estos pacientes, generalmente sometidos a terapias inmunosupresoras por largo tiempo ${ }^{2,8-11}$. En relación a la artritis reumatoídea, es importante destacar que existen varios reportes que indican un aumento de 
nódulos pulmonares reumatoídeos, algunas veces cavitados, en pacientes con terapia con antiTNF alfa $^{12-14}$.

Causas misceláneas incluyen la Histiocitosis de células de Langerhans (principalmente en fumadores), el COP (Cryptogenic organizing pneumonia), hamartomas, malformaciones arteriovenosas, Neumoconiosis (asbestosis, silicosis), cuya cavitación es inusual y hace necesario descartar Tuberculosis ${ }^{1,2}$.

Considerando la amplia lista en el diagnóstico diferencial de los nódulos pulmonares cavitados, es el contexto clínico, asociado al laboratorio y la imagenología, lo que permitirá orientar la sospecha diagnóstica. En este caso particular, la ausencia de una clínica característica dificultó la orientación etiológica previo al resultado de la biopsia.

En el contexto de una paciente con mal control metabólico de su diabetes, que se presenta con nódulos pulmonares cavitados, se debe sospechar la presencia de infecciones como Tuberculosis y fúngicas invasoras, en especial Mucormicosis y Aspergilosis. Sin embargo, el buen estado general de la paciente y la ausencia de otros compromisos como el rinosinusal, lo hacía menos probable, aunque no totalmente descartable.

El antecedente de tabaquismo activo importante, sugería la posibilidad de un cáncer pulmonar cavitado, pero una vez más, el buen estado de la paciente, la presencia de múltiples lesiones, la ausencia de clínica como hemoptisis, de alteraciones de laboratorio y por sobre todo, de adenopatías mediastínicas, alejaron dicho diagnóstico.

Si bien desde el punto de vista imagenológico, la Granulomatosis con poliangeítis era una opción probable, hubo aspectos clínicos y de laboratorio que alejaron dicho diagnóstico como la primera opción etiológica. En primer lugar, la ausencia de síntomas asociados (rinosinusales, neuropáticos, cutáneos) y de compromiso renal inicial, considerando que las alteraciones del primer examen de orina eran explicables por su nefropatía diabética. En segundo lugar, la presencia de un ANCA positivo por IFI con patrón perinuclear y un ANCA por ELISA negativo (lo cual ocurre sólo en el 5-10\% de las GPA). Esto determinó que la biopsia se transformara en el pilar fundamental del diagnóstico y con ello, de la toma de decisiones terapéuticas.

El interés del caso presentado está en relación a la presencia de una Granulomatosis con poliangeítis con extenso compromiso pulmonar cavitario, pero con escasos síntomas, y serología atípica, lo cual obliga a tener siempre presente esta enfermedad como parte del diagnóstico diferencial de nódulos pulmonares cavitados, a pesar de que el contexto clínico sea poco sugerente.

\section{Bibliografía}

1. RYU J H, SWENSEN S J. Cystic and cavitary lung diseases: focal and diffuse. Mayo Cli Proc 2003; 78: 744-52.

2. GADKOWSKI B, STOUT J. Cavitary pulmonary disease. Clin Microbiol Rev 2008; 21: 305-33.

3. CHUNG M P, YI C A, LEE H Y, HAN J, LEE K S. Imaging of pulmonary vasculitis. Radiology 2010; 255 : 322-41.

4. ABERLE D S, GAMSU G, LYNCH D. Thoracic manifestations of Wegener Granulomatosis: diagnosis and course. Radiology 1990; 174: 703-9.

5. HERNÁNDEZ L, CORREA G, FOSTER C, ALLER F, FERNÁNDEZ C, NEIRA O. Nódulos pulmonares cavitados y vasculitis ANCA asociada, secundarios a infección por Zigomicetos. Rev Chil Reumatol 2009; 25: 167-70.

6. GÓMEZ-PUERTA J A, HERNÁNDEZ-RODRÍGUEZ J A, LÓPEZ-SOTO A, BOSCH X. Antineutrophil cytoplasmic antibody-associated vasculitides and respiratory disease. Chest 2009; 136: 1101-11.

7. CHOI H Y, IM J-G, HAN B-K, KIM J H, LEE K Y, MYOUNG N H. Thoracic manifestations of ChurgStrauss syndrome: radiologic and clinical findings. Chest 2000; 117: 117-24.

8. NANIWA T, MAEDA T, SHIMIZU S, ITO R. Hepatitis $\mathrm{B}$ virus related-polyarteritis nodosa presenting with multiple lung nodules and cavitary lesions. Chest 2010; 138: 195-7.

9. KARADAG F, POLATLI M, SENTURK T. Cavitary necrobiotic nodule imitating malignant lung disease in a patient without articular manifestations of rheumatic arthritis. J Clin Rheumatol 2003; 9: 246-52.

10. WINNE L, PRAET M, BRUSSELLE G, VEYS E, MIELANTS H. Bilateral spontaneous pneumothorax in a patient with pulmonary rheumatoid nodules, secondary infected by Aspergillus. Clin Rheumatol 2007; 26 : 1180-2.

11. HIGHTON J, HUNG N, HESSIAN P, WILSHER M. Pulmonary rheumatoid nodules demonstrating features usually associated with rheumatoid synovial membrane. Rheumatology 2007; 46: 811-4.

12. HÜBSCHER O, RE R, LOTTI R. Pulmonary rheumatoid nodules in an etanercept-treated patient. Arthritis Rheum 2003; 48: 2077-8.

13. VAN EDE A, DEN BROEDER A, WAGENAAR M, VAN RIEL P, CREEMERS M. Etanercept-related extensive pulmonary nodulosis in a patient with rheumatoid arthritis. J Rheumatol 2007; 34: 1590-2.

14. TOUSSIROT E, BERTHELOT JM, PERTUISET E, BOUVARD B, GAUDIN P, WENDLING D, et al. Pulmonary nodulosis and aseptic granulomatous lung disease occurring in patients with rheumatoid arthritis receiving tumor necrosis factor-alpha-blocking agent: a case series. J Rheumatol 2009; 36: 2421-7.

\footnotetext{
Correspondencia a:

Dr. Daniel Erlij O.

Sección Reumatología, Hospital del Salvador

Avda Salvador 364. Santiago, Chile.

Email: danerlij@gmail.com
} 